\title{
EVALUASI PENGUNJUNG TERHADAP LAYANAN DI PERPUSTAKAAN GANESHA SMA N 1 JETIS BANTUL
}

\author{
Safutri Surniawati \\ Pustakawan SMA Negeri 1 Jetis Bantul \\ email: Safutri9putri@gmail.com
}

\begin{abstract}
Abstrak
Layanan adalah suatu hal pokok yang harus ada di perpustakaan. Perpustakaan sekolah tentunya mempunyai karakter yang berbeda dari perpustakaan yang lain, yang konsep layanannya disesuaikan dengan karakter peserta didik. Tolok ukur keberhasilan perpustakaan adalah seberapa puas pustakawan akan layanan yang diberikan guna memenuhi kebutuhan baik untuk mencari informasi maupun pemanfaatan perpustakaan sebagai sarana rekreasi dan penelitian. Perpustakaan Ganesha memiliki beberapa jenis layanan diantaranya; Layanan Informasi, Layanan Referensi, Layanan Sirkulasi, Layanan Serial, Layanan Baca Ditempat, Layanan Fotokopi, Layanan Bebas Pustaka, Layanan Bercerita, Layanan Anak, Layanan Pojok Baca, dan Layanan Pemutaran Film. Layanan yang disediakan sudah terjadwal dengan berkala, sehingga perpustakaan Ganesha melaksanakan program layanan tersebut dengan tertib dan baik. Tujuan penelitian ini adalah (1) Mendiskripsikan jenis layanan yang terdapat pada perpustakaan Ganesha. (2) Untuk mengevaluasi pengunjung dalam layanan perpustakaan.

Dalam penelitian ini pengumpulan data yang digunakan ialah metode observasi. Subjek penelitian ini adalah petugas perpustakaan SMA N 1 Jetis Bantul.Hasil penelitian dapat disimpulkan bahwa ada kecenderungan penurunan jumlah pengunjung dari bulan febuari 54,49\% ke bulan april $16,77 \%$. Hal ini disebabkan oleh persiapan ujian kelas XII serta kurang beragamnya jumlah dan jenis sumber informasi yang dimiliki oleh perpustakaan SMA N 1 Jetis Bantul. Adanya sifat proaktif dari pustakawan terhadap mutu layanan yang diberikan kepada pemustaka juga turut andil dalam membuat daya Tarik untuk pemustaka agar berkunjung ke perpustakaan. Informasi lebih lanjut tentang perpustakaan Ganesha dapat di akses informasi koleksi melalui web http://lib.sman1jetis.sch.id.
\end{abstract}

\section{A. PENDAHULUAN}

Dunia online yang menjadi gaya hidup saat ini tentunya menjadi peran dan fungsi perpustakaan bergeser. Koleksi-koleksi cetak sudah jarang disentuh, beberapa pemustaka lebih asyik menggeser layar gawai ke kiri kanan atas dan bawah. Hal ini tidak hanya terjadi dalam perpustakaan daerah, perpustakaan perguruan tinggi hingga perpustakaan sekolah juga mengalami hal yang sama. Konsep yang ditawarkan perpustakaan harus yang selalu berinovasi untuk mengikuti perkembangan zaman sehingga perpustakaan selalu menjaga eksistensinya.

Perpustakaan sekolah merupakan unit perpustakaan yang terdapat di sekolah dasar hingga menengah, tentunya keberadaannya diharapkan dapat membantu dalam kegiatan dan proses belajar mengajar. Dengan adanya manajemen yang baik, perpustakaan sekolah akan tetap menjadi pusat sumber belajar pustakawan terutama pelajar. Dengan meningkatkan layanan perpustakaan adalah salah satu upaya pustakawan serta pengelola mengembangkan peran serta fungsi guna memenuhi kebutuhan siswa dalam mengolah informasi.

Layanan perpustakaan sekolah yang telah dikelola oleh pustakawan diharapkan dapat memenuhi kebutuhan dan keinginan hingga tercapainya kepuasan pemustaka. Layanan perpustakaan tentunya akan berbeda di setiap instansi sesuai dengan kebutuhan dan keinginan serta karakteristik peserta didik. Dengan berbagai ragam pustakawan dan siswa yang dilayani maka akan menghasilkan jenis layanan yang berbeda pula, tentunya dalam hal ini akan menambah variasi jenis layanan perpustakaan sekolah. 
Beberapa layanan yang terdapat di perpustakaan sekolah umumnya layanan yang bersifat langsung maupun tidak langsung, ada beberapa perpustakaan yang telah menerapkan layanan TI untuk memenuhi kebutuhan siswa. Ada beberapa perpustakaan juga yang membuka layanan ekstensi, yakni layanan untuk pemustaka non anggota. Hal ini dapat juga menjadi sarana promosi perpustakaan tentunya diharapkan dapat meningkatkan pengunjung dan pengguna perpustakaan.

Perpustakaan Ganesha SMA N 1 Jetis Bantul adalah objek yang akan diteliti jenis layanannya. Disini peneliti akan mencari tahu terkait macammacam pelayananan yang terdapat di perpustakaan Ganesha SMA N 1 Jetis Bantul. Oleh karena itu, pada penelitian ini rumusan masalah yang diangkat ialah, apa saja senis layanan yang ada di perpustakaan Ganesha SMA N 1 Jetis Bantul, dan bagaimana evaluasi layanan di perpustakaan Ganesha SMA N 1 Jetis Bantul? Sementara tujuan dari penelitian ini ialah untuk mengetahui jenis layanan yang ada di perpustakaan Ganesha SMA N 1 Jetis Bantul serta untuk mengevaluasi pengunjung terhadap layanan di perpustakaan Ganesha SMA N 1 Jetis Bantul.

\section{B. KAJIAN TEORITIS}

Evaluasi produktivitas layanan utama perpustakaan kota dengan menggunakan contoh 48 perpustakaan umum besar dan 44 perpustakaan umum kecil dari Ceko dan Republik Slovakia dilakukan sesuai dengan dekomposisi indeks Malmquist berorientasi input (MI). Hasil MI yang dicapai dievaluasi menggunakan interval kepercayaan dan metode bootstrap. Produktivitas layanan utama perpustakaan umum dipelajari untuk tahun 2016 dibandingkan dengan tahun 2012. Rata-rata, perpustakaan kecil maupun besar menunjukkan penurunan produktivitas yang signifikan secara statistik. Nilai rata-rata MI perpustakaan kecil adalah 1,29 . Nilai rata-rata MI perpustakaan besar adalah 1,16 . Memburuknya produktivitas disebabkan oleh efisiensi input yang lebih rendah. Perpustakaan kecil maupun besar rata-rata menunjukkan tingkat produktivitas yang sebanding di kedua tahun yang diteliti. Kesimpulan ini sama untuk perpustakaan Ceko dan Slovakia serta semua perpustakaan bersama. Perpustakaan Ceko, jika dibandingkan dengan yang Slovakia, mencapai hasil yang lebih baik dalam hal produktivitas. Produktivitas yang lebih tinggi dari perpustakaan Ceko dibandingkan dengan yang Slovakia disebabkan oleh peningkatan efisiensi input, bukan oleh perubahan teknologi (Vrabková \& Friedrich, 2019).

Layanan perpustakaan ialah fasilitas dan aktivitas perpustakaan yang memberikan jasa layanan terhadap pemustaka tanpa membeda-bedakan.Sehingga pemustaka sebagai pengguna perpustakaan perlu terus diperhatikan dan di layani dengan sebaik-baiknya. Perpustakaan adalah suatu lembaga yang memberikan layanan informasi secara cuma-cuma kepada pemustaka.

Sutarno berpendapat bahwa layanan perpustakaan ialah suatu kegiatan utama dalam perpustakaan yang dimana layanan tersebut merupakan kegiatan yang langsung berhubungan dengan masyarakat dan sekaligus tolok ukur keberhasilan perpustakaan (Sutarno, 2006). Dalam setiap pelayanan perpustakaan merupakan kegiatan yang memberikan layanan yang baik , yang sebagaimana diinginkan oleh pemakai dalam menyampaikan informasi. Menurut Darmono, definisi layanan perpustakaan ialah suatu kegiatan yang menawarkan jasa layanan dalam bentuk koleksi yang dimiliki perpustakaan kepada pemakai dengan datang ke perpustakaan dan menginginkan informasi yang dibutuhkannya (Darmono, 2001). Dalam hal ini perpustakaan merupakan tempat terjadinya interaksi antara pustakawan yang membutuhkan pelayanan pustakawan.

Sistem layanan perpustakaan terdiri dari layanan terbuka dan tertutup Sistem Sistem Pelayanan terbuka(open acces) ialah sistem layanan 
yang dapat diakses oleh para pemustaka untuk menemukan, dan mengambil sendiri bahan pustaka secara langsung dari jajaran rak koleksi perpustakaan yang diinginkan oleh pemustaka. Sedangkan sistem layanan tertutup (close acces) ialah sistem layanan yang bahan koleksinya tidak dapat diambil sendiri oleh pemustaka,sehingga akan dilayani oleh petugas perpustakaan, pustakawan akan mengambilkan atau melayani pemustaka untuk koleksi yang dibutuhkan/diinginkan (Darmono, 2001). Sedangkan menurut Lasa jenis layanan yang terdapat di perpustakaan diantaranya; layanan sirkulasi, layanan referensi, layanan penelusuran informasi, layanan fotokopi, layanan baca ditempat, layanan internet, layanan kelas alternatif, layanan reproduksi, layanan terjemahan, layanan pinjam antar perpustakaan, layanan konsultasi, dan layanan pendidikan pemustaka atau bimbingan pemakai (Lasa, 2016).

\section{METODE PENELITIAN}

Penelitian dilakukan di SMA N 1 Jetis Bantul dengan metode kualitatif. Penelitian berlangsung selama bulan Oktober 2019. Peneliti menggunakan teknik observasi untuk mengetahui jenis-jenis layanan di perpustakaan Ganesha. Pengumpulan data dilakukan dengan observasi dan pengamatan langsung di lokasi penelitian. Selain observasi juga dilakukan dengan wawancara kepada kepala perpustakaan maupun pustakawannya. Sumber data penelitian, diperoleh dari data statistik dan dokumentasi yang dimiliki oleh Perpustakaan Ganesha Bantul.

\section{HASIL DAN PEMBAHASAN}

\section{A. Jenis Layanan yang Ada di Perpustakaan Ganesha}

Perpustakaan Ganesha SMA N 1 Jetis Bantul Yogyakarta telah terakreditasi A pada tahun 2018. Perpustakaan Ganesha telah meraih juara 2 lomba perpustakaan tingkat Nasional yang tentunya sudah mengembangkan beberapa komponen dalam pemenuhan kebutuhan pemustaka.

Layanan yang terdapat di perpustakaan merupakan salah satu fasilitas yang disediakan oleh perpustakaan. Kepuasan pemustaka merupakan tingkat keberhasilan dari layanan perpustakaan. Tolok ukur prestasi perpustakaan ialah kemampuan melakukan layanan prima dan bermutu kepada pelanggannya. Layanan perpustakaan merupakan jasa pemberian informasi kepada pemustaka secara cepat dan tepat kepada pemustaka. Pelayanan perpustakaan merupakan semua rangkaian aktivitas perpustakaan yang diberikan kepada pemustaka dalam bentuk penyediaan sarana dan prasarana beserta koleksi secara memadai sehingga kebutuhan informasi dan sumber bcaan pemustaka dapat terpenuhi.

Atas dasar uraian tersebut di atas dapat dipahami, bahwa perpustakaan merupakan suatu lembaga yang berorientasi pada layanan jasa nirlaba sebagai media belajar sepanjang hayat bagi masyarakat yang dilayaninya.

\section{Layanan Informasi}

Layanan yang disediakan perpustakaan untuk pemustaka yang ingin mengetahui tentang Perpustakaan Ganesha maupun mencari informasi yang ada di perpustakaan. Layanan ini ada setiap hari dan akan dilayani oleh duta baca yang sedang bertugas dan atau pustakawan.

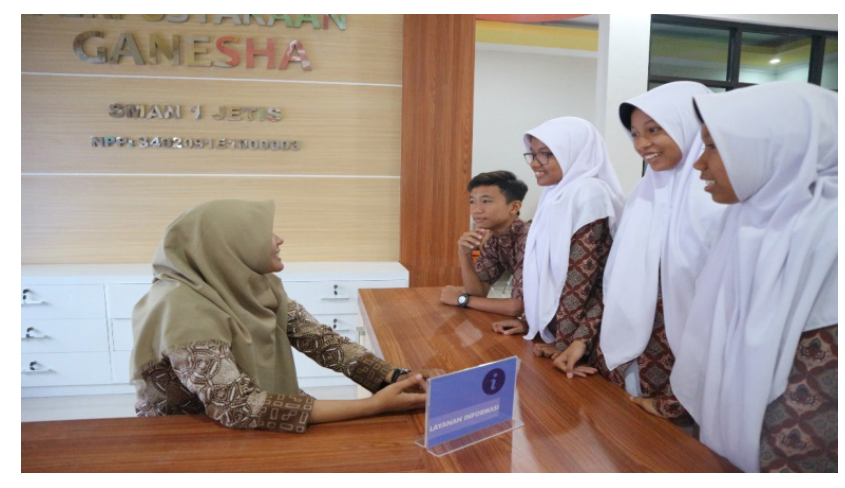

Gb. 1. Pustakawati sedang memberikan informasi tentang perpustakaan Ganesha kepada pemustaka 


\section{Layanan Rujukan}

Layanan rujukan adalah suatu kegiatan pelayanan perpustakaan yang diperuntukkan untuk pemustaka dalam memperoleh sumber bacaan dan memberi bimbingan/arahan agar menemukan informasi yang diinginkan. Pelayanan ini bertujuan membantu pengguna perpustakaan dalam memperoleh sumber bacaan dan bimbingan praktis dalam menemukan sebuah tema tertentu. Sumber bacaan yang digunakan oleh pemustaka dalam menjawab pertanyaan dari pemustaka, biasanya berupa kamus, ensiklopedi, almanak, buka pegangan, atlas, dan sebagainya.

\section{Layanan Sirkulasi}

Sistem pelayanan ini menggunakan sistem layanan terbuka untuk pencarian koleksi dan sistem layanan tertutup untuk peminjaman serta pengembalian. Sistem tertutup yaitu pemustaka dapat mencari koleksi secara mandiri, sedangkan sistem terbuka yaitu jika pemustaka ingin meminjam dan mengembalikan harus melalui petugas sirkulasi.

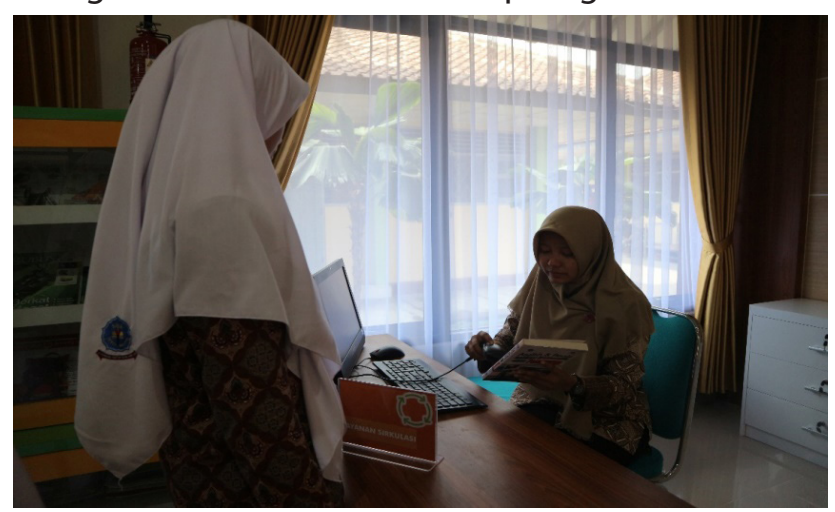

Gb. 2. Pelayanan sirkulasi,peminjaman buku

\section{Layanan Serial}

Layanan serial menggunakan sistem terbuka (open access) sehingga pemustaka dapat mencari koleksi secara mandiri. Koleksi serial hanya dapat dibaca ditempat. Pemustaka yang ingin memfotocopy koleksi dapat menghubungi petugas, mengisi buku peminjaman dan meninggalkan kartu identitas.

\section{Layanan Baca Ditempat}

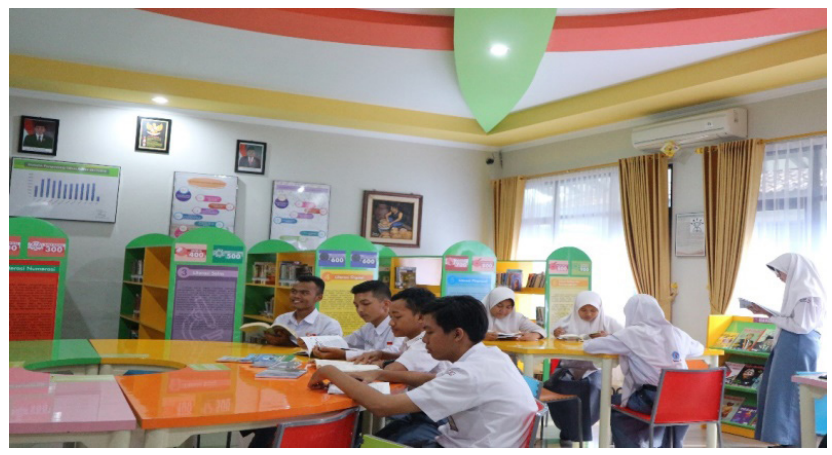

Gb. 3. Siswa sedang membaca buku di ruang baca terbuka

Layanan baca ditempat merupakan bentuk layanan perpustakaan Ganesha yang menyediakan tempat atau ruang untuk pemustaka membaca koleksi perpustakaan. Layanan ini dibuat semenarik mungkin sehingga pemustaka merasa nyaman.

\section{Layanan Fotokopi}

Pemustakan yang ingin memfotokopi koleksi, dapat menghubungi petugas perpustakaan. Layanan ini disediakan untuk siswa yang membutuhkan referensi atau memfotokopi tugas-tugas. Layanan fotokopi berada di lantai 1, pada layanan ini siswa dipersilakan untuk membayar dengan sukarela.

\section{Layanan Bebas Pustaka}

Setiap pemustaka berhak mendapatkan surat bebas pustaka ketika sudah tidak memiliki tanggungan pinjaman dan denda. Surat bebas pustaka merupakan syarat untuk pengambilan ijazah.

\section{Layanan Bercerita}

Layanan bercerita di perpustakaan Ganesha diselenggarakan untuk mengasah sekaligus meningkatkan kemampuan siswa dalam mencerna informasi. Layanan ini juga berkesinambungan dengan layanan anakyang terdapat di perpustakaan Ganesha dan diadakan setiap satu bulan sekali. 


\section{Layanan Anak}

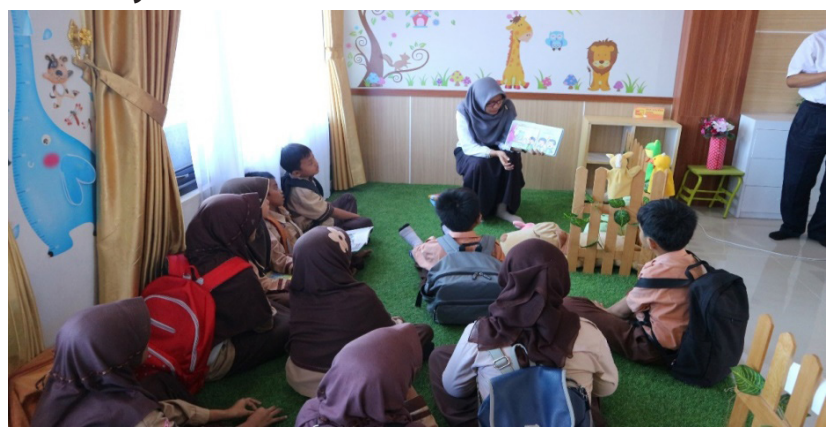

Gb. 4. Kegiatan mendongeng(Layanan Anak) kepada siswa SD

Layanan Anak adalah layanan yang diberikan kepada masyarakat (anak-anak) melalui pendayagunaan koleksi untuk pembaca seperti buku cerita, mendongeng, dan terdapat permainan yang beredukasi dan rekreasi.

\section{Layanan Pojok Baca}

Layanan pojok baca pada perpustakaan Ganesha terdiri dari dua macam, yang pertama layanan pojok baca dalam dan kedua layanan pojok baca luar. Pertama layanan pojok baca dalam yaitu layanan pojok baca yang terdapat di lingkungan SMA Negeri 1 Jetis yang tersebar di beberapa titik. Antara lain, kantin, hall, BK, dan UKS. Kedua layanan pojok baca luar yaitu layanan pojok baca berada di luar lingkungan SMA Negeri 1 Jetis, diantaranya terdapat di Puskesmas Jetis, Polsek Jetis, dan di Bank BPD cabang Jetis.

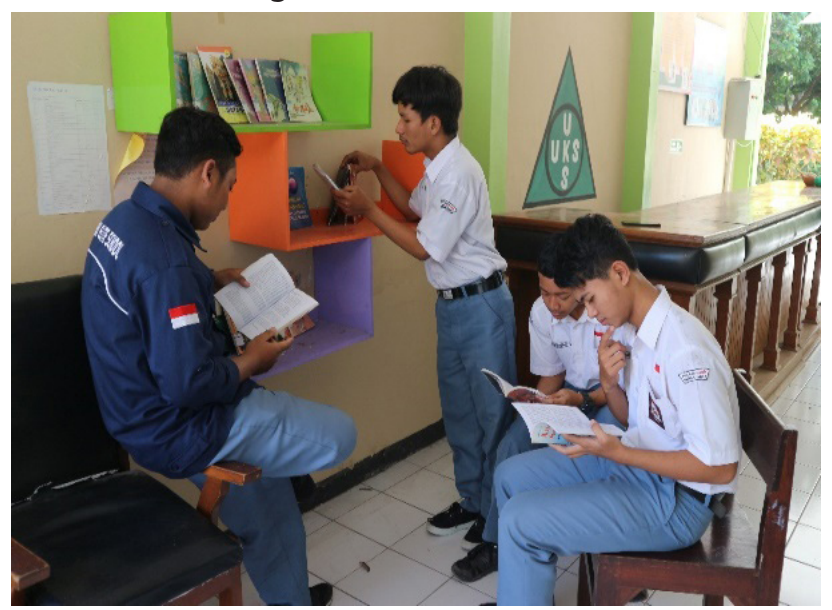

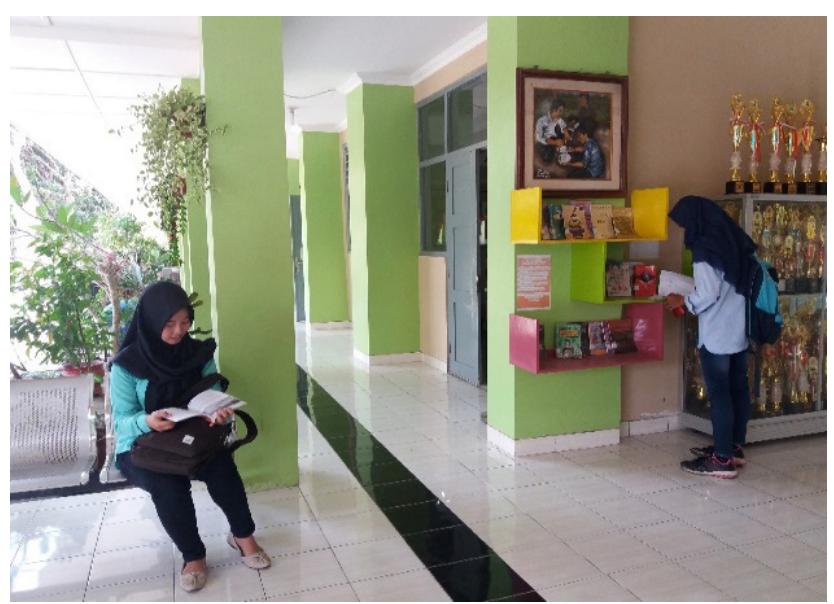

Gb. 5. Foto sebelah kanan orang tua wali murid sedang membaca buku di Pojok Baca yang berada di ruang lobi,dan foto sebelah kiri, siswa sedang membaca buku di Pojok Baca sebelah ruang UKS.

\section{Layanan Pemutaran Film}
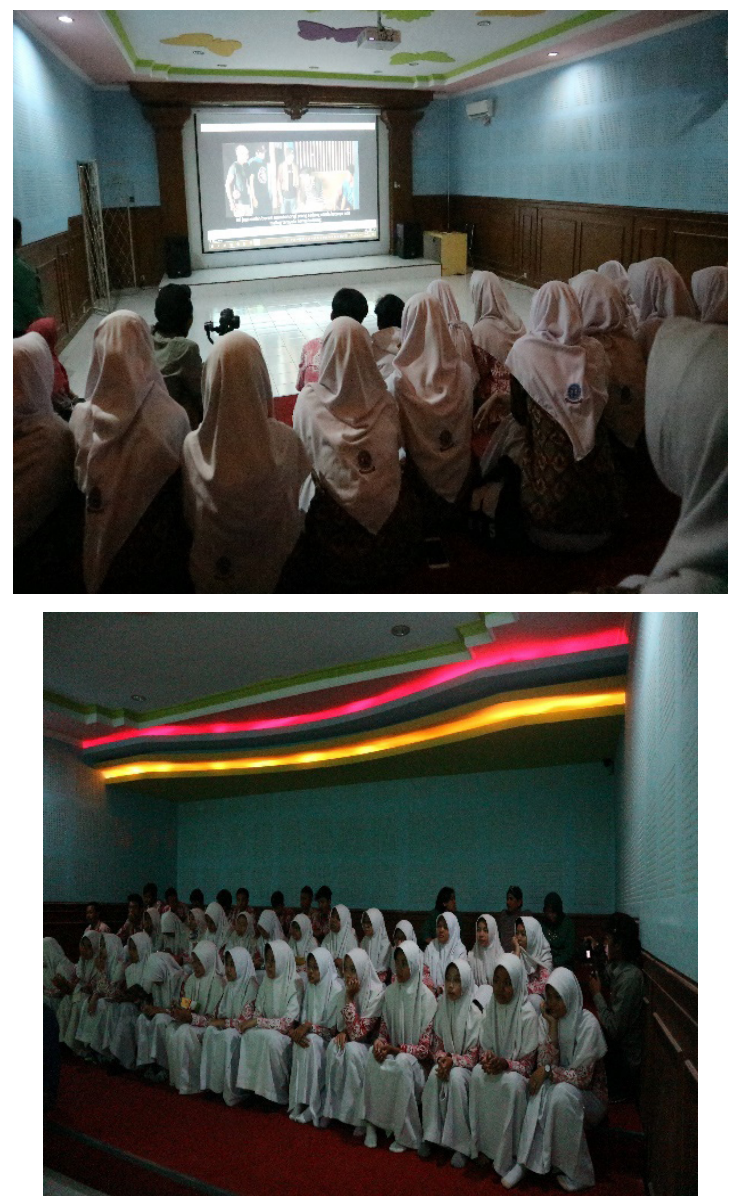

Gb. 6. Siswa-siswi melihat pemutaran film, di ruang audiovisual yang berada di Layanan Pemutaran Film

Sumber: Perpustakaan SMA Negeri 1 Jetis Bantul

Layanan pemutaran film diadakan setiap hari Jumat setelah kegiatan belajar mengajar selesai 
di ruangan audiovisual. Pemutaran film ditujukan sebagai sarana rekreasi siswa dan belajar tentang pembelajaran yang dapat diambil dari sebuah tayangan. Film yang diputar sudah disediakan oleh pustakawan. Siswa yang akan mengikuti kegiatan ini harus mendaftrakan diri sehari sebelum pemutaran film.

\section{B. Evaluasi Pengunjung Terhadap Layanan Perpustakaan}

Tabel 1. Statistik jumlah pengunjung pada tahun 2018 Perpustakaan SMA N 1 Jetis Bantul

\begin{tabular}{|c|c|c|c|}
\hline No. & Bulan & Jumlah Pengunjung & \% \\
\hline 1. & Februari & 2602 & 32,11 \\
\hline 2. & Maret & 2735 & 33,76 \\
\hline 3. & April & 2764 & 34,11 \\
\hline
\end{tabular}

Sumber: Data Statistik SMA N 1 Jetis Bantul

Tabel 2. Statistik jumlah pengunjung pada tahun 2019 Perpustakaan SMA N 1 Jetis Bantul

\begin{tabular}{|c|c|c|c|}
\hline No. & Bulan & Jumlah Pengunjung & $\%$ \\
\hline 1. & Februari & 2602 & 32,11 \\
\hline 2. & Maret & 2735 & 33,76 \\
\hline 3. & April & 2764 & 34,11 \\
\hline
\end{tabular}

Sumber: Data Statistik SMA N 1 Jetis Bantul

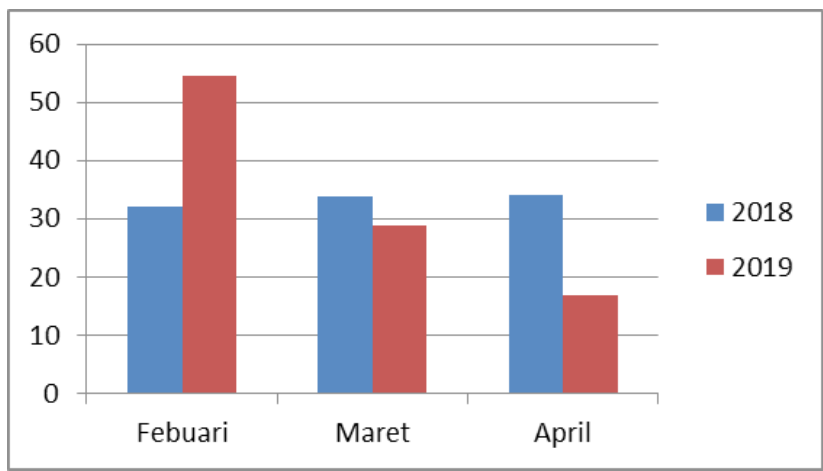

Sumber: Perpustakaan Ganesha SMA N 1 Jetis Bantul

Pada tabel 1 diatas dapat dilihat bahwa pengunjung dari bulan febuari sampai dengan bulan april mengalami peningkatan.Sedangkan pengunjung tertinggi terjadi pada bulan april sebesar $34,11 \%$. Karena persiapan UAS pada kelas X\&XI sehingga siswa mencari dan mendalami materi yang akan diujikan dengan berkunjung keperpustakaan,dengan memanfaatkan koleksi yang ada di perpustakaan ganesha.

Pada tabel 2 diatas dapat dilihat bahwa pengunjung pada bulan Februari sampai dengan bulan april mengalami penurunan.Pengunjung pada bulan april mengalami penurunan sebesar $16,77 \%$ dikarenakan sedang ujian kelas XII ,sehingga yang berkunjung ke perpustakaan berkurang karena kelas X \& XI libur.

\section{A. PENUTUP}

\section{Simpulan}

Di perpustakaan Ganesha SMA N 1 Jetis Bantul pada bulan febuari sampai april tahun 2018 mengalami peningkatan pengunjung meskipun hanya 2\%. Sedangkan pada bulan febuari sampai dengan bulan april 2019 mengalami penurunan yang signifikan yaitu $37,72 \%$. Sehingga perpustakaan Ganesha perlu meningkatkan pelayanan serta diadakannya kegiatan yang dapat membuat daya tarik bagi pemustaka agar berkunjung ke perpustakaan.

\section{Saran}

Layanan yang masih belum optimal karena luasnya lokasi perpustakaan.Agar layanan yang telah ada bisa dilaksanakan sesuai dengan yang telah diinginkan,sehingga perlu adanya buku kendali di setiap layanan, agar kepala perpustakaan dan pustakawan dapat melakukan evaluasi terkait jalannya kegiatan layanan. 
UNI ib Jurnal Perpustakaan Vol. 11 No.2 Tahun 2020 : 142-149

\section{DAFTAR PUSTAKA}

Darmono. (2001). Manajemen Perpustakaan.

Grasindo Eastwood.

Lasa, H. (2016). Manajemen Perpustakaan Sekolah/

Madrasah. Ombak.

Sutarno. (2006). Manajemen Perpustakaan (2nd ed.). Sagung Seto.

Vrabková, I., \& Friedrich, V. (2019). The productivity of main services of city libraries: Using the example from the Czech Republic and the Slovak Republic. Library \& Information Science Research, 41(3). 
